\title{
NOTAS PARA UMA GEOMETRIA DA INOGÊNGIA EM MARIA GABRIELA LLANSOL
}

Cinzia Russo (Università degli Studi di Trieste)

Recebido a 8/11/2018. Aceite a 15/4/2019.

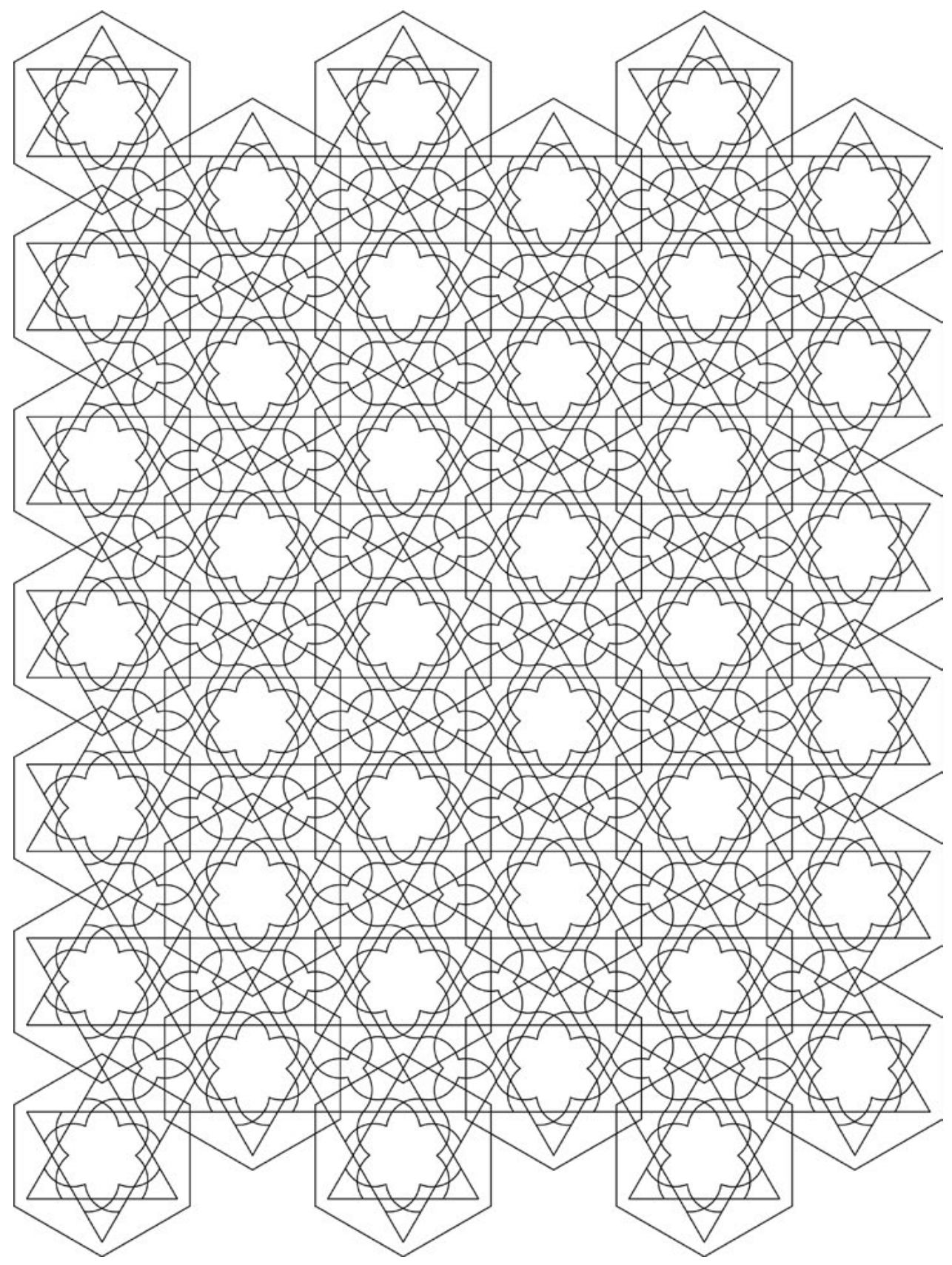


Resumo: O artigo aborda o tema da polissemia do «toque» na obra de Maria Gabriela Llansol e do grande poder criador que possui essa acção. $\mathrm{O}$ «toque» inocente abre caminho para um outro espaço originário e imaginante de jogo e de conhecimento. Abre a "porta" a que a autora chama o «mútuo», um lugar de encontro e de conversa amorosa, onde o amor nos espera a sós. Qualquer ser que passe por aquela «porta», sabe que tem uma possibilidade de crescimento segundo a sua própria lei. Ninguém pode renunciar a sua própria lei de crescimento, sob pena de morrer: essa é a sua maneira de viver nesse espaço. $\mathrm{O}$ encontro com o «mútuo» «proporciona» a cada ser a possibilidade de seguir o seu fim específico. Viver assim significa ter uma magnífica capacidade de conhecer e uma extraordinária apetência de conhecimento. «Nesse espaço, viver é ir à procura do conhecer». Procuremos viver. Vamos viver no querer conhecer.

Palavras-chave: Inocência. Toque. Mútuo. Memória. Conhecimento.

Abstract: The theme of this article is the polysemy of «touch» in the work of Maria Gabriela Llansol and the great creative power that this action has. The innocent «touch» opens a way to another original and imaginary space of playing and of knowledge. It opens the «door» that the author calls the «mutual», a place of meeting and loving conversation, where love awaits us alone. Any person who passes through that «door» knows that he or she has a possibility of growth according to his or her own law. No one can renounce his or her own law of growth, on penalty of dying: that law is his or her peculiar way of living in that space. The encounter with the «mutual» gives each being the possibility of following its specific purpose. To live this way means to have a magnificent capacity to know and an extraordinary appetite for knowledge. «In this space, to live is to search with the aim to knowing.» Let's try to live. Let's live in the aiming to know.

Keywords: Innocence. Touch. Mutual. Memory. Knowledge.

«Perdi muito tempo imaginando que [o] toque [inocente] vestia a substância» e permitia conhecer ${ }^{1}$. São as palavras significativas que Maria Gabriela Llansol diz nas primeiras páginas de O jogo da liberdade da alma. Já no começo do livro ela aborda o tema da polissemia do «toque» - «tocar a uma porta, tocar em alguém, tocar um instrumento»-, já nos primeiros capítulos fala do «toque leve de um vestido sobre a pele» e do grande poder criador que possui essa acção ${ }^{2}$. Fala do antigo hábito que tinha de vestir a substância, de orná-la com um tecido delicado. Recorda quando em Jodoigne compunha vestidos para o seu corpo e como a partir do figurino, do corte, do juntar as peças, do coser, do provar,

1 Maria Gabriela Llansol, O jogo da liberdade da alma, Lisboa, Relógio d'Água, 2003, p. 29.

2 Ibid. 
da procura de um adereço, se sentia crescer como um cisne vogando através das águas de um lago ${ }^{3}$. $\mathrm{O}$ «toque» tem imenso poder. $\mathrm{O}$ «toque» não é «fixo» nem «cercado». O poder do «toque» flui, cria uma «narrativa interminável» - um «toque a rebate», um «toque em falso», um «toc como eram os adereços da substância». Ela corria e a saia batia-lhe no corpo e «[abria-se] em poder de evocação». Felicidade, tristeza e leveza alternavam-se nela quando surgia e ressurgia por entre o movimento do vestido sobre a pele ${ }^{4}$. No entanto, às vezes o «toque» abria uma racha lateral na saia e caía para o chão «a impostura da língua», o seu poder de ficção, o que não é bom procurar ${ }^{5}$. Na sua vida a autora sempre procurou coser, unir as costuras de um vestido, sentir-se como se sentia quando o fazia ou pelos menos ser o que a música era naqueles momentos. Quando o conseguia, para ela era um júbilo, tornava-se «uma realidade fulgurante, uma muralha de resistência ao medo e ao nada», ressurgia ${ }^{6}$. Nesse processo a fala acompanhava-a, os fios da língua entrelaçavam-se com o saber que soltava o «toque». Sem a língua que dá nome e ordena, sem «Témia, [...] a rapariga que temia a impostura da língua» e tentava dar uma orientação clara, uma direcção certa à palavra, no sentido de não trair o primeiro pensamento de que parte, esse saber volveria ao $\operatorname{caos}^{7}$. Não conseguiria ter voz e a língua acabaria sendo um impulso cadente ${ }^{8}$. «O corpo é materialmente frases». «[O] material e $[\mathrm{o}]$ literal não têm diferentes». ${ }^{9}$

A frase solta com que começámos o nosso breve ensaio sobre Maria Gabriela Llansol: «Perdi muito tempo imaginando que [o] toque [inocente] vestia a substância» e permitia conhecer, este fragmento que não é a obra mas é já obra, é um terreno de sementeira onde germina o pensamento da autora. Nele desabrocham ideias que se encontram de forma mais desenvolvida e diferentemente contextualizada em seus outros livros. Trata-se de um momento de escrita reverberante, incisivo e luminoso em que fazem a sua aparição os elementos estruturais do tema da inocência. Os conceitos que nos permitem urdir a trama do que queremos tratar: o «toque» «inocente» e o «conhecimento». A matéria de que é feita a nossa reflexão e que impulsiona o nosso movimento nessas páginas. A mesma matéria que nos permite ganhar esse corpo e essa existência de papel.

Comecemos a analisar o primeiro dos termos sobre que se assenta a nossa reflexão: o «toque». Comecemos a ver que forma assume e qual é o papel que desempenha. Na pluralidade de sentidos que a palavra toma no livro $O$ jogo da liberdade da alma, descobre-se que há uma constante: o contacto. $\mathrm{O}$ contacto da coisa no corpo e do corpo na coisa. É um contacto que gera consequências imprevisí-

3 Cf. Ibid., p. 30.

4 Ibid., p. 31.

5 Ibid., pp. 30-31.

6 Ibid.

7 Id., Na casa de Fulho e Agosto, Lisboa, Relógio d'Água, 2003, p. 164.

8 Cf. Id, A palavra imediata. Livro de Horas IV, Porto, Assírio \& Alvim, 2014, p. 142.

9 Id. ${ }^{\circ}$ jogo da liberdade da alma, cit., p. 11. 
veis. É um contacto que abre caminho para um outro espaço, um espaço originário e imaginante de jogo e de conhecimento. Muitas são as descrições do toque-contacto que encontramos no livro. Os capítulos estão cheios de tais descrições. «Um corpo [avança] no silêncio do que diz» ${ }^{10}$. O vestido cobre-o. A mão de uma rapariga corre sobre o «tecido branco matizado com flores» ${ }^{11}$. Ela acaricia o vestido como se fosse uma cortina ${ }^{12}$. Puxa-o, move-o. Tacteia-o, sente-o, explora-o como se fosse uma gaveta para abrir ${ }^{13}$. Com o dedo indicador e o dedo polegar percorre a consistência fechada do rebordo branco. «Algo de ondulante e de directo [...], esconde[-se] do outro lado, da parte interior do vestido» ${ }^{14}$. A rapariga aproxima-se da «porta». Entra pela «porta»e dá com uma mulher numa relação luminosa ${ }^{15}$. É uma cena fulgor. É uma pausa no retracto ${ }^{16}$. A criança atravessa o fulgor ${ }^{17}$. Com «a saia que lhe bate nas pernas» passeia através desse fulgor ${ }^{18}$. É um momento estático e extático. O toque-contacto do tecido no corpo abre a «porta» a que a autora chama o «mútuo», um lugar de encontro e de conversa amorosa, um espaço-outro, neutro e impessoal onde o amor nos espera a sós ${ }^{19}$ e é fonte de Sabedoria ${ }^{20}$. Nele «o amante pede ao amante um "para sempre, estar lá", pede-lhe que não pare de brincar, que subam juntos, com outros que vêm ou se avizinham, a escada de Jacob» ${ }^{21}$. Qualquer ser que passe por aquela «porta», sabe que tem uma possibilidade de crescimento segundo a sua própria lei. Ninguém pode renunciar a sua própria lei de crescimento, sob pena de morrer: essa é a sua maneira de viver nesse espaço ${ }^{22}$. O encontro com o «mútuo» «proporciona» a cada ser a possibilidade de seguir o seu fim específico. $\mathrm{O}$ encontro com o «mútuo» «proporciona» a cada ser a possibilidade de subir a escada de Jacob segundo a sua própria lei. Não é uma qualquer subida. Não é uma qualquer subida espiritual. É mais da ordem da «grafia», como acontece no livro com a palavra «xale», «xaile» e «chaile», ou então da ordem da «sobreposição», como se vê na subida de Aossêt $\hat{e}^{23}$ ao

10 Ibid., p. 61.

11 Ibid., p. 35.

12 Cf. Ibid., p. 43.

13 Cf. Ibid., p. 51.

14 Ibid., p. 55.

15 Id., Na casa de Julho e Agosto, cit., p. 155.

16 Cf. Id., Ojogo da liberdade da alma, cit., p. 56.

17 Cf. Ibid.

18 Ibid., p. 57.

19 Id., Finita, Lisboa, Assírio \& Alvim, 2005, p. 134.

20 Cf. Ibid., p. 197.

21 Id., Na casa de Julho e Agosto, cit., p. 149.

22 Cf. Ibid., p. 142.

23 É o nome que Maria Gabriela Llansol dá a Fernando Pessoa. Chama-o dessa maneira e deixa vários indícios sobre ele nos seus livros. 
monte $^{24}$. Em qualquer conversa amorosa, em qualquer fraseado, no meio de uma frase os amantes levitam. Crescem móveis e novos no espaço da sua cena interior ${ }^{25}$. Os corpos querem encontrar-se no «mútuo», conversar no «mútuo», crescer nele, ser seres crescendo nele. Augusto Joaquim, o marido e companheiro de vida e de escrita de Maria Gabriela Llansol, no posfácio à segunda edição do seu segundo diário Finita, a propósito disso, escreve: «O mútuo começa por ser o que, em tempos, se chamava "conversação espiritual", mas desenvolvendo-se em relação textual, física (como se diz do acto de amor), cuja dinâmica ou sentido [principal] é a mutação dos seres». O «mútuo» é o autêntico motor da mudança e da metamorfose. De qualquer encontro os participantes saem modificados. $\mathrm{O}$ seu traço distintivo é a mutação do $\operatorname{ser}^{26}$. No «mútuo» admiram-se as regras da sintaxe amorosa que nos obrigam ser, que nos obrigam advir. Ainda escreve Augusto Joaquim: «Só no encontro com o amante o homem [pode] advir» ${ }^{27}$. Viver assim significa ter uma magnífica capacidade de conhecer e uma extraordinária apetência de conhecimento. «Nesse espaço, viver é ir à procura do conhecer» ${ }^{28}$.

Agora vamos debruçar-nos sobre a qualidade do «toque». Agora vamos considerar os atributos que o «toque» assume nas páginas. Cândida é a forma que tomam os seres que se inclinam ao movimento e a crescer $^{29}$. Para a autora a candura é luz. No livro O jogo da liberdade da alma os seres que se movem e crescem, adquirem uma maior luminosidade, uma maior claridade ${ }^{30}$. São «luar» ${ }^{31}$, «luar libidinal» ${ }^{32}$. São fósforos acesos que oscilam pelo grande espaço ${ }^{33}$. No uso que a escritora faz da língua, as palavras cruzam outras, atravessam outras, adquirem matéria plástica e sonora, adquirem um seu próprio ritmo e uma sua própria densidade. Nessa corrida as palavras sobrepõem-se, estratificam-se, construindo ulteriores níveis de realidade. Ulteriores níveis de realidade porque outros, ulteriores níveis de realidade porque possíveis ${ }^{34}$. Na cena da inocência surge subitamente a «juventude desmemoriada». Ela aumenta e confirma a escrita. Confirma a escrita da candura-luz e acrescenta outra. As duas juntas ajudam a descobrir a substância. A única possibilidade de acorde com a substância é vê-la. Vê-la por um lado através da escrita constituída pela candura-luz e por outro através da escrita constituída pela «juventude desmemoriada» ${ }^{35}$. A ideia de «juventude» faz a sua entrada no livro $O$

24 Cf. M. G. Llansol, Na casa de Julho e Agosto, cit., p. 144 e p. 149.

25 Cf. Ibid., p. 142 e p. 148.

26 Cf. Id., Finita, cit., p. 240.

27 Ibid., p. 239.

28 Id., Na casa de Julho e Agosto, cit., p. 142.

29 Cf. Id., Finita, cit., p. 191.

30 Cf. Ibid., p. 196.

31 Id., O jogo da liberdade da alma, cit., p. 79.

32 Ibid., p. 52.

33 Cf. Ibid., p. 23.

34 Id., Finita, cit., p. 210.

35 Id., O jogo da liberdade da alma, cit., p. 15. 
jogo da liberdade da alma com a palavra «rapariga» ${ }^{36}$ que logo, e na medida em que o movimento do ser se acentua, é substituída pela palavra «criança» ${ }^{37}$. Quando o processo de evolução do ser está no começo, a «juventude» tem a forma de uma rapariga que vive noutra época e de que se não vê o rosto ${ }^{38}$, da «rapariga desmemoriada» que «procura o vestido que traz vestido» ${ }^{39}$, de «Témia» ${ }^{40}$, a jovem que temia a impostura da língua ${ }^{41}$. Quando o ser já sabe ler a substância, a «juventude» assume a forma de uma «criança», da «criança» que «saltou para o chão» ${ }^{42}$, da «criança que saltou para o chão e foi brincar com as vacas no prado da Louise» ${ }^{43}$. Presenciamos um ir para trás. Damos passos para trás. Vamos ao encontro da infância. Damos um passo para trás mas num crescendo de candura e de luz. Na medida em que nos aproximamos da origem da vida, a brancura e o brilho deslumbram-nos. Essa é a hora certa para que no jogo entre a memória, ou melhor, a falta de memória, o desaparecimento do «passado» que torna o «presente» possível. Essa é a hora certa para que no palco faça a sua aparição «a memória de anão», «a memória de quem não tem grande memória», a única que permite ao «presente» falar ${ }^{44}$. Agora é altura de que «a rapariga desmemoriada até do seu próprio nome» atravesse a cena ${ }^{45}$. Ela e as outras que andam pelas páginas, têm em comum duas coisas: a extrema juventude e uma memória organizada em rede, em cereja, diria um matemático, para fazer de comunicativo, quando se escapa toda a construção matemática ${ }^{46}$. Nela alguma memória habita mas tão diáfana e subtil que lhe é difícil dar nomes aos objectos ou objectos aos nomes ${ }^{47}$. A sua memória é tão evanescente que se não sabe se está desmemoriada dos nomes ou das coisas dos nomes. Se não sabe se toca no tecido desmemoriada do seu som ou da sua substância. Vemo-la afastar o tecido das vidraças e encostar a sua queixa à luz do dia. Ouvimo-la murmurar: «Onde está o vestido que passa pelo pensamento?» ${ }^{48}$. Sem uma «memória decidida» os objectos flutuam ${ }^{49}$. É-lhe complicado iniciar um esboço de inventário, descrever as brevíssimas ou levíssimas diferenças que, por comparação, sobressaem. Cada objecto aparece-lhe lentamente, tacteando-o, percorrendo-o com os dedos. Num

36 Ibid., p. 21.

37 Ibid., p. 52.

38 Ibid., p. 28.

39 Ibid., p. 33.

40 Ibid., p. 58.

41 Cf. Id., Na casa de Julho e Agosto, cit., p. 164.

42 Id., O jogo da liberdade da alma, cit., p. 52.

43 Ibid., p. 55.

44 Id., «Sou um canibal de olhos...», separata de A Phala, 2009, pp. 5, 1.

45 Id., O jogo da liberdade da alma, cit., p. 33.

46 Cf. Ibid., p. 34.

47 Cf. Ibid., p. 35.

48 Ibid., p. 34.

49 Ibid., p. 37. 
passo de $O$ jogo da liberdade da alma a autora diz: «Enquanto a [sua] mão percorria o espaldar, vi formar-se lentamente uma diferença imanente, uma presença ausente que já antes lhe roçara o corpo, e se esvaíra ${ }^{50}$. Ter um resto de memória, é absorver o presente numa constante iniciação, encontrar-se num estado de nudez ${ }^{51}$. A «rapariga desmemoriada» anda pelo quarto. Toma o mundo à volta por um conjunto de coisas para descobrir. Sem som, sem nome, sem qualquer referido, caminha entre a porta e as vidraças ${ }^{52}$. Naquele quarto, é ela o único autor que nele há ${ }^{53}$. «Inocente» atravessa o espaço. Mede com grandes passos o pequeno lugar. Surpreendida descobre aquela parte de mundo. No terreno da experiência nascem as formas sólidas, talvez doces, talvez mortais. Na deambulação que não tem tréguas, adquirem vida e sentido os objectos sem memória ${ }^{54}$.

O assunto da falta de memória - o pouco sei e o pouco decoro, no sentido de «memorizo» ${ }^{55}-$, introduz o terceiro elemento da nossa reflexão sobre a inocência em Maria Gabriela Llansol: o «conhecimento». É um «conhecimento» que a autora chama de «intuitivo», em que a lógica não é o dono ${ }^{56}$. É um «conhecimento» que tem que ver com o jogo. É um «conhecimento» que nasce no jogo. No jogo com o objecto, a imagem, o sonho, o discursivo e a escrita ausente. Nesse jogo dão-se imensas possibilidades $^{57}$. Esse jogo exige a nossa presença. Esse jogo exige que nós olhemos. «Olhar é completamente diferente de analisar e de compreender, é apanhar o que flui num instante único, sem [memória], sem crítica, fazendo coincidir o acontecimento com o seu espectáculo» ${ }^{58}$. Significa olhar com atenção para «o que poderia vir a ser, o que viria a ser» ${ }^{59}$. Significa olhar com atenção para o quadro dos nossos olhos, o quadro dos nossos ouvidos, «o quadro de vozes simultâneas, de uma mulher de meia idade sentada, de um jovem de pé, e de um homem ainda jovem, antes da idade madura, que procura as duas no fundo da sala», parafraseando a escritora ${ }^{60}$. No livro O jogo da liberdade da alma a autora procura dar uma definição do que é o «conhecimento intuitivo». Lê-se no texto: «Um corpo rola no silêncio do que diz, há uma memória que se cala, um espelho reflecte um beijo e, a seguir, um ombro nu. Podes crer, esta é a primeira definição do conhecimento intuitivo» ${ }^{61}$. Témia, «a rapariga

50 Ibid., p. 35.

51 Cf. Ibid.

52 Cf. Ibid., p. 41.

53 Cf. Ibid., p. 43.

54 Ibid., p. 45.

55 Id., «Sou um canibal de olhos...», cit., p. 1.

56 Id., O jogo da liberdade da alma, cit., p. 56.

57 Cf. Id., Na casa de Fulho e Agosto, cit., pp. 147-148.

58 Id., A palavra imediata. Livro de Horas IV, cit., p. 23.

59 Id., O jogo da liberdade da alma, cit., p. 45.

60 Id., A palavra imediata. Livro de Horas IV, cit., p. 41.

61 Id., O jogo da liberdade da alma, cit., p. 61. 
que temia a impostura da língua ${ }^{62}$, quer ver oralmente ${ }^{63}$. Desde o início, quando se encontrava em Herbais a encerar o chão, uma vez parecendo sofrer e outras nem tanto, quer conhecer. Agora dir-se-ia que está feliz ${ }^{64}$. Enquanto pousa a mão no espaldar da cadeira e inclina o busto, olhando com curiosidade para o tecido que lhe bate nas pernas, sorri. Contente toca no tecido branco matizado com flores que lhe cobre o corpo. Ao vê-la tocar no tecido, Maria Gabriela Llansol diz: «Matéria». E repete: «Matéria». E, absorta em seus pensamentos, acrescenta: «Matéria-prima, linhas» ${ }^{65}$. Percorrendo com os dedos indicador e polegar o forro interior, a «criança que saltou para o chão», diz, alegre: «Vestido». É o primeiro nome que dá ao que se afasta da sua memória, ao que lhe aparece lentamente tacteando ${ }^{66}$. Há um diálogo entre ela e o vestido. Tudo o que tem vida, tem ternura ${ }^{67}$. A «rapariga» vai buscar um vestido e deixa que esse vestido lhe mostre o sítio em que ondulam, por sopro da memória ausente, as suas pregas ${ }^{68}$.

Somos seres de diversas matérias. Temos traços de luz que invadem as nossas conversas interiores e nos mostram o caminho. O caminho a escolher é o do «vestido». $\mathrm{O}$ caminho certo é esse mesmo ${ }^{69}$. Temos que ir ter com a «criança que saltou para o chão e foi brincar com as vacas no prado da Louise ${ }^{70}$. Estamos conscientes de que temos de ir para trás dela, vê-la correr por entre as vacas. Estamos conscientes de que temos de seguir os seus passos, se queremos aprender a ler substância ${ }^{71}$. $\mathrm{O}$ que importa é passar a vida a não morrer $^{72}$. O que importa é procurar existir. Frequentemente a gente confunde a «realidade» com a «existência». O que é real nem sempre existe e o que existe nem sempre é real. «Há muito real que não consegue existir, e há muitíssima existência que não tem (nem nunca teve) realidade alguma» ${ }^{73}$. Procuremos existir. Vamos existir no querer conhecer. Vamos existir no trabalho magnífico de querer conhecer. Corre Témia, corre nosso eu, nosso dela, abre a clareira dentro do escuro ${ }^{74}$. Corre, corre segura. Não sucumbas à desenvoltura da língua, à sua impostura e

62 Id., Na casa de Fulho e Agosto, cit., p. 164.

63 Id., O jogo da liberdade da alma, cit., p. 63.

64 Cf. Ibid., p. 34.

65 Ibid., pp. 34-35.

66 Cf. Ibid., p. 39.

67 Cf. Ibid., p. 92.

68 Ibid., p. 51.

69 Cf. Ibid., p. 53.

70 Ibid., p. 55.

71 Gf. Ibid.

72 Cf. Ibid., p. 56.

73 Id., Na casa de Julho e Agosto, cit., p. 156.

74 Cf. Id., O jogo da liberdade da alma, cit., p. 58. 
à sua flutuação75. Dá um passo em frente. Não hesites. Não tenhas medo. Corre, corre. É preciso pouca coragem para dar esse passo em frente. Basta pensar ir a caminho. Inscrever essa conjectura no «vestido» e ir a caminho76.

\section{REFERÊNGIAS BIBLIOGRÁFICAS}

LLANSOL, Maria Gabriela (2014), A palavra imediata. Livro de Horas IV, Porto, Assírio \& Alvim. (2009), «Sou um canibal de olhos...», separata de A Phala, pp. 1-8. (2005), Finita, Lisboa, Assírio \& Alvim. (2003), Na casa de Fulho e Agosto, Lisboa, Relógio d'Água. (2003), O jogo da liberdade da alma, Lisboa, Relógio d'Água.

75 Cf. Ibid., p. 70 e p. 84.

76 Ibid., p. 87. 